\title{
Analysis of Springback Behaviour in Micro Flexible Rolling of Crystalline Materials
}

\author{
Feijun Qu, ${ }^{1}$ Zhengyi Jiang $\mathbb{D}^{1,2}$ Xiaogang Wang $\mathbb{D}^{, 2}$ and Cunlong $\mathrm{Zhou}^{2}$ \\ ${ }^{1}$ School of Mechanical, Materials, Mechatronic and Biomedical Engineering, University of Wollongong, Northfields Avenue, \\ Wollongong 2522, Australia \\ ${ }^{2}$ Shanxi Province Metallurgical Equipment Design Theory and Technology Key Laboratory \\ (Provincial Department to Build National Key Laboratory Training Base), Taiyuan University of Science and Technology, \\ Taiyuan 030024, China
}

Correspondence should be addressed to Xiaogang Wang; wxg@tyust.edu.cn

Received 8 May 2018; Revised 18 September 2018; Accepted 19 September 2018; Published 15 November 2018

Academic Editor: Donato Sorgente

Copyright (C) 2018 Feijun Qu et al. This is an open access article distributed under the Creative Commons Attribution License, which permits unrestricted use, distribution, and reproduction in any medium, provided the original work is properly cited.

\begin{abstract}
This paper presents a constitutive modelling of the polycrystalline thin metal strip under a state of combined loading in microflexible rolling. The concept of grained inhomogeneity is incorporated into the classic Chaboche hardening model that accounts for the Bauschinger effect, in order to provide more precise description and analysis of the springback mechanism in the particular forming operation. The model is first implemented in the finite element program ABAQUS to numerically predict the stress-strain relationship of 304 stainless steel specimens over a range of average grain sizes. After validation of the developed model by comparison of predicted curves and actual stress-strain data points, it is further applied to predict the thickness directional springback in microflexible rolling of 304 stainless steel strips with initial thickness of $250 \mu \mathrm{m}$ and reduction changing from 5 to $10 \%$. The model predictions show a reasonable agreement with the experimental measurements and have proven to be more accurate than those obtained from the conventional multilinear isotropic hardening model in combination with the Voronoi tessellation technique. In addition, the variation of thickness directional springback along with the scatter effect is compared and analysed in regard to the average grain size utilising both qualitative and quantitative approaches in respect of distinct types of data at different reductions.
\end{abstract}

\section{Introduction}

Rolling technology has been investigated extensively in the last few decades, during which theory and research have been formulated by using a combined analytical and numerical approach $[1,2]$. However, thanks to the increasing popularity of miniaturisation in modern industrial development over recent years, it has been promising to look into the flexible rolling process of micrometer thick materials, whereof the overall dimensions as well as the longitudinal thickness profiles of the workpieces may be adapted to the requirements of the microapparatus and systems. Pioneering investigations into the microflexible rolling process have been conducted with respect to the rolling force, the elastic recovery in thickness direction of the workpiece, the surface roughness evolution related to different process variables, and so forth [3-6]. Due to the thinness of the material, the thickness directional springback of the rolled workpiece, mainly caused by the elastic redistribution of the internal stresses upon removal of the rolling force, can lead to failure to produce a predefined thickness profile along rolling direction [7]. Consequently, an appropriate control for the springback is worthy of more attention and deeper examination.

One basic approach to the regulation of springback attempts to reduce or compensate for it through modification of process parameters or adjustment in tool design. For instance, Anggono et al. [8] developed a hybrid algorithm to rectify the springback error by iterative comparison between the deformed and target shapes, which provided a faster correction with a smaller deviation from the desired 
dimension during a U-channel forming case. Wang et al. [9] presented an incremental bending methodology to minimise the springback error in air bending process by utilising the data gathered from loading-unloading cycles, based on which the workpiece thickness, and material properties could be more accurately assessed and then used to calculate the final punch position to achieve the target bend angle. An irritation with a high-power diode laser was deployed by Gisario et al. [10] to control the extent of the springback by selectively heating the bent area in $\mathrm{V}$-shape bending of aluminium alloy sheets. With regard to the flat rolling process, automatic gauge control technology has been widely adopted to create real-time adjustments of the roll gap in accordance with the feedback of the workpiece exit thickness, so as to correct the difference between the desired and actual thicknesses induced by springback [11-13]. Nevertheless, the cost and unpredictability of springback compensation can be reduced providing that the springback potential is recognised prior to the actual manufacturing [14].

As a consequence, springback prediction is becoming progressively more significant in metal forming processes and has been increasingly dependent upon numerical modelling and simulation techniques in recent years. For instance, Ankènas and Barauskas [15] presented numerical evaluation of springback of sidewall and flange under various process conditions in U-shaped deep drawing with mild steel materials. Wagoner and Li [16] estimated the suitability of different numerical integration schemes as well as the number of through-thickness integration points in terms of springback accuracy in a beam bending model, which was reported to vary with material properties, $R / t$ values, and sheet tensions. Sumikawa et al. [17] led a probe into the influence of material behaviour on the accuracy of springback analysis, and then developed a material model with a consideration of elastoplastic anisotropy and Bauschinger effect to further improve the accuracy of springback prediction during the hat-shaped forming using high-strength steel sheets. Furthermore, Wang et al. [18] proposed an analysis model based on the surface layer model and composite model to predict the unloading springback of copper alloy sheets in microscaled U-bending process, taking into account the interactive influence of geometry size, grain size, and punch radius. The pattern of the size effects affecting the springback was disclosed by the numerical simulations, physical experiments, and the comparison in-between. Diehl et al. [19] performed finite element simulations to reveal the variation of springback angle in relation to different material grain sizes and strain gradients in free bending of thin aluminium foils with thickness to the order of micrometers. Jiang and Chen [20] numerically investigated the grain size effect on the springback behaviour of microtubes in press bending process, and they discovered that the springback amount decreased with a decrease in thickness to average grain size (T/D) ratio for microtubes with a constant wall thickness and varying average grain size, whereas it decreased with an increase in $\mathrm{T} / \mathrm{D}$ ratio for microtubes with constant average grain size. Since the springback phenomenon is closely related to the residual stress after the part has been released from the forming tools, a proper characterisation of residual stress may enhance the accuracy of springback prediction, which nonetheless highly depends on the modelling of material behaviour during the forming process [21].

For decades, numerous investigators have observed the constitutive behaviour of different materials subjected to an assortment of forming operations involving cyclic loading or complex loading conditions, under which the Bauschinger effect has widely been acknowledged, namely, the reduction of yield stress upon load reversals, which is usually accounted for by the release of dislocations piling up at the grain boundaries during initial deformation [22]. Prager [23] and Ziegler [24] first developed the linear kinematic hardening models to describe the Bauschinger effect, and the difference between their models was reflected by the translation direction of the yield surface. Later, Armstrong and Frederick [25] and Chaboche [26] modified these linear models into nonlinear ones by adding an extra term so as to capture the transient behaviour and reproduce the ratcheting in fatigue. Since then, increasing and diverse demands have encouraged improvements in either the ArmstrongFrederick model or the Chaboche model, such as to control the evolution of the decomposed kinematic hardening rules by Ohno and Wang [27, 28], define effective quantities in stress and plastic strain rate by Chung and Richmond [29], or incorporate the permanent softening along with the Bauschinger effect and transient behaviour by Chun et al. $[30,31]$. Besides, two-surface models have been formulated by Krieg [32] and Dafalias and Popov [33] to define a continuous variation of hardening between these two surfaces, namely, that the evolution of the inner surface characterises the transient response of the material, whereas the evolution of the outer surface represents the long-term response of the material such as the Bauschinger and softening phenomena. McDowell [34] introduced a twosurface stress space model by incorporating the effects of changes in plastic strain range and nonproportionality of loading in the evolution of isotropic hardening in order to enhance the prediction accuracy of complex nonproportional deformation behaviours like cyclic ratcheting, mean stress relaxation, etc. D. Kim and J. Kim [35] developed a two-surface model for rate-dependent plasticity by combining both isotropic and kinematic hardening rules. This model was validated through both monotonic and cyclic loading cases using structural steels, where simulation results exhibited an excellent agreement with experimental values in terms of the maximum stress and shape of hysteresis. Hashiguchi [36] incorporated a subloading surface within the inner surface of the two-surface model so as to express the smooth elastic-plastic transition, avoiding an abrupt change of the strain rate/stress rate relationship when loaded from the stress state within the inner surface. Moreover, a multisurface model was proposed by Mroz [37] to combine properties of isotropic and kinematic workhardening via a configuration of surfaces of constant workhardening moduli, which specified an expression for the general features of the cyclic loading behaviour as well as a smooth transition from the elastic to plastic deformation. 
These models have been set up and adopted primarily to describe the constitutive characteristics of materials at the macroscale; nevertheless, the so-called size effects, including geometry size, grain size, and grained inhomogeneity effects, cannot be negligible when constructing constitutive models will be applied on the microscale. For instance, Lu et al. [38] established a microscale constitutive model on the basis of grain size, shape, deformability, and specimen dimension to discuss the deformation behaviours of polycrystalline copper grain with different grain and feature sizes in microforming processes, like microcompression and microcross wedge rolling. According to the dislocation theory, Jiang et al. [39] proposed a constitutive model with consideration of forming temperature, Hall-Petch relationship and surface layer model to investigate the influences of temperature and grain size on the deformability of pure copper in microcompression process, where both factors were found to significantly affect the shape accuracy of the produced product, as well as the metal flow behaviour due to material heterogeneity. Liu et al. [40] developed a novel constitutive model to characterise the effects of grain size and boundary and geometry size on the flow stress of pure copper foils as well as on the microextrusion of CuZn30 alloy billets. Utilising the surface layer model, they divided the specimen into two portions, viz., surface layer and inner portions, while the grains of the inner portion were further divided into two portions, viz., grain interior and grain boundary. Likewise, Wang et al. [41] built a comprehensive constitutive model on the basis of surface layer model with consideration of the influences of grain size, material thickness, grain number through thickness, and surface property. The developed model was employed to predict the mechanical properties of thin sheet metal, and the results were compared with the physical experimental results, which confirmed that their model was particularly suitable for thin sheets with one or several grains across the thickness.

In this study, a nonlinear elastic-plastic constitutive model incorporating the two yield surface constitutive model as well as the Chaboche kinematic hardening rule is developed with the aim to give a more accurate mathematical description of the anisotropic workpiece responding to the complex loading during microflexible rolling process, thus enhancing the prediction accuracy of thickness directional springback after unloading. The newly constructed model is integrated into the ABAQUS geometric modelling, utilising the user-defined subroutine user material (UMAT) as an interface. Firstly, this model is validated by simulating the miniature tensile test and comparing results with experiments using 304 stainless steel specimens. Secondly, different constitutive/numerical models are employed to characterise the mechanical behaviour and predict the thickness directional springback during microflexible rolling of $250 \mu \mathrm{m}$ thick 304 stainless steel strips with reduction of 5 to $10 \%$. Thirdly, laboratory-scale microflexible rolling experiments are carried out to further verify and validate this novel model which produces more accurate predictions than the multilinear isotropic hardening model and the Voronoi tessellation based model. Finally, both simulation and experimental results of thickness directional springback are quantitatively revealed with respect to the average grain size, and the scatter effect caused by grained inhomogeneity is analysed synchronically in regard to the average grain size in a qualitative manner.

\section{Constitutive Modelling Based on the Concept of Grained Inhomogeneity}

2.1. Elastic-Plastic Mixed-State Model. It has been stated that the diversity of grains leads to the heterogeneous mechanical response of the whole granular material, viz., that grains with low yield strength may have suffered plastic deformation while those with higher yield strength are still in their elastic realm at a certain applied stress $[5,6]$. The yield anisotropy of this kind can be abstractly described using two yield surfaces metaphorically termed "initial yield surface" and "complete yield surface", which specify the transition from elastic deformation to mixed elasticplastic deformation and that from mixed elastic-plastic deformation to plastic deformation, respectively.

As von Mises yield criterion has been adopted to analyse the constitutive behaviour of the rolled material, these two yield surfaces can be generally expressed by (for the planestress condition, $\left.\sigma_{3}=0\right)$ [42]

$\begin{cases}F_{1}\left(\boldsymbol{\sigma}_{i j}, \boldsymbol{\alpha}_{i j}, k_{1}\right)=f_{1}-k_{1}=0 & \text { (for initial yield surface) } \\ F_{2}\left(\boldsymbol{\sigma}_{i j}^{\prime}, \boldsymbol{\alpha}_{i j}^{\prime}, k_{2}\right)=f_{2}-k_{2}=0 & \text { (for complete yield surface) }\end{cases}$

where $f_{1}=1 / 2\left(s_{i j}-\boldsymbol{\alpha}_{i j}\right)\left(s_{i j}-\boldsymbol{\alpha}_{i j}\right)$ and $f_{2}=1 / 2\left(s_{i j}^{\prime}-\boldsymbol{\alpha}_{i j}^{\prime}\right)$ $\left(s_{i j}^{\prime}-\boldsymbol{\alpha}_{i j}^{\prime}\right)$, in which $\boldsymbol{\alpha}_{i j}$ and $\boldsymbol{\alpha}_{i j}^{\prime}$ are the position tensors of the centres of the initial yield surface $F_{1}$ and complete yield surface $F_{2}$ in the stress space, respectively, associated with the deformation history of and the hardening rule for the material, whilst $k_{1}=1 / 3 \sigma_{s}^{2}\left(\overline{\varepsilon_{p}}\right)$ and $k_{2}=1 / 3 \sigma_{s}^{\prime 2}\left(\overline{\varepsilon_{p}}\right)$, in which $\sigma_{s}$ and $\sigma_{s}^{\prime}$ represent the sizes of these two yield surfaces, depending on the equivalent plastic strain

$$
\overline{\varepsilon_{p}}=\int \sqrt{\frac{2}{3}}\left(d \varepsilon_{i j}^{p} d \varepsilon_{i j}^{p}\right)^{1 / 2},
$$

where $d \boldsymbol{\varepsilon}_{i j}^{p}$ denotes the components of the plastic strain increment. The relationship between the size of the yield surface and the effective plastic strain may be acquired by the uniaxial tensile test. The two surfaces are assumed to be of the identical form, having nearly parallel normal vectors at points $\sigma_{i j}$ and $\sigma_{i j}^{\prime}$ on $F_{1}$ and $F_{2}$, respectively.

In accordance with the applied stress, there are probably three stress states in the material, to wit, pure elastic, mixed elastic-plastic, and complete plastic. The constitutive laws for each stress state are described as follows:

(a) For the pure elastic state: The sizes and centres of $F_{1}$ and $F_{2}$ remain unchanged for the applied stress, $\sigma$ is within the initial yield surface $F_{1}$, and only elastic strain occurs during this state. In the light of generalised Hooke's law, the relationship of stress to elastic strain is expressed as

$$
\boldsymbol{\sigma}=D_{e}: \boldsymbol{\varepsilon}_{e}
$$


where $\boldsymbol{D}_{e}$ is the constant elasticity tensor. Note that Equation (3) remains applicable for the elastic states of the material during mixed elastic-plastic loading and plastic loading.

(b) For the mixed elastic-plastic state: During the mixed elastic-plastic loading, the size and centre of $F_{2}$ maintain their originality whereas $F_{1}$ keeps its size unaltered, but its centre evolves (i.e., the Bauschinger effect) until these two yield surfaces make contact with $\boldsymbol{\sigma}_{i j}$ brought to coincide with $\boldsymbol{\sigma}_{i j}{ }^{\prime}$, which indicates the commencement of plastic loading. Based upon Ziegler's linear kinematic hardening rule, the evolution of the centre of $F_{1}$ (the back-stress $\boldsymbol{\alpha}_{i j}$ ) can be written as [24]

$$
d \boldsymbol{\alpha}=d \mu\left(\boldsymbol{\sigma}_{i j}^{\prime}-\boldsymbol{\sigma}_{i j}\right)
$$

where $d \mu$ is dependent on the material. Equation (4) states that $F_{1}$ moves in a translation in the direction of the vector connecting the two stress points $\sigma_{i j}$ and $\boldsymbol{\sigma}_{i j}^{\prime}$.

Due to the coexistence of both elastically and plastically deformed grains, a weighted heterogeneity coefficient $\bar{\xi}[5]$ is adopted to reflect the proportion, namely, that $\bar{\xi} / 2$ represents the ratio of strain occurring in the elastically deformed grains, whereas $(1-\bar{\xi} / 2)$ is formulated to represent the ratio of strain occurring in the grains that have entered the plastic region. From this point of view, the stress-strain relationship in the mixed elastic-plastic state follows that

$$
\begin{aligned}
& \boldsymbol{\sigma}=D_{e}: \boldsymbol{\varepsilon}_{e 1}=D_{e}: \boldsymbol{\varepsilon}_{e 2}, \\
& \boldsymbol{\varepsilon}=\frac{\bar{\xi}}{2} \boldsymbol{\varepsilon}_{1}+\left(1-\frac{\bar{\xi}}{2}\right) \boldsymbol{\varepsilon}_{2}=\frac{\bar{\xi}}{2} \boldsymbol{\varepsilon}_{e 1}+\left(1-\frac{\bar{\xi}}{2}\right)\left(\boldsymbol{\varepsilon}_{e 2}+\boldsymbol{\varepsilon}_{p 2}\right),
\end{aligned}
$$

where $\bar{\xi}$ belongs to the interval $[0,2], \boldsymbol{\varepsilon}_{e 2}$ and $\boldsymbol{\varepsilon}_{p 2}$ are the elastic and plastic parts of the strain occurring in the plastically deformed grain, respectively.

(c) For the complete plastic state: After the material undergoes plastic deformation, it is postulated that the size of $F_{1}$ expands but its centre remains invariable, while both the size and centre of $F_{2}$ evolve following the Chaboche kinematic hardening rule, taking into account the complex loading conditions, such as compression and torsion, that may exist in the actual microflexible rolling process [43-45].

According to the basic form of the Chaboche model, the strain is partitioned into elastic and plastic parts, which, in the small strain hypothesis, can be formulated by [26]

$$
\varepsilon=\varepsilon_{e}+\varepsilon_{p}
$$

and Equation (3) still illustrates the relationship between the stress and elastic strain during the plastic loading.

For yield surface $F_{2}$, the kinematic hardening evolution of the back-stress $\boldsymbol{\alpha}^{\prime}$ is composed of three nonlinear terms as follows [46, 47]:

$$
\begin{gathered}
\boldsymbol{\alpha}^{\prime}=\boldsymbol{\alpha}_{1}^{\prime}+\boldsymbol{\alpha}_{2}^{\prime}+\boldsymbol{\alpha}_{3}^{\prime}, \\
d \boldsymbol{\alpha}_{1}^{\prime}=\frac{2}{3} C_{1} d \boldsymbol{\varepsilon}_{p}-a_{1} \boldsymbol{\alpha}_{1}^{\prime} d \overline{\varepsilon_{p}}, \\
d \boldsymbol{\alpha}_{2}^{\prime}=\frac{2}{3} C_{2} d \boldsymbol{\varepsilon}_{p}-a_{2} \boldsymbol{\alpha}_{2}^{\prime} d \overline{\varepsilon_{p}}, \\
d \boldsymbol{\alpha}_{3}^{\prime}=\frac{2}{3} C_{3} d \varepsilon_{p}-a_{3} \boldsymbol{\alpha}_{3}^{\prime} d \overline{\varepsilon_{p}},
\end{gathered}
$$

where $a_{1}, a_{2}, a_{3}, C_{1}, C_{2}, C_{3}$ are material parameters, $\boldsymbol{\varepsilon}_{p}$ and $\overline{\boldsymbol{\varepsilon}_{p}}$ are the plastic strain and effective plastic strain, respectively. The evolution of isotropic hardening takes the following form [46]:

$$
k_{2}=Q\left(1-\exp \left(-b \overline{\varepsilon_{p}}\right)\right)
$$

where $Q$ defines the maximum change in the size of $F_{2}$, and $b$ indicates the rate of change in the size of $F_{2}$ as plastic deformation develops. Then the change in the size of $F_{1}$ can be evaluated by [48]

$$
k_{1}=k_{2} \cdot \frac{\boldsymbol{\sigma}-\boldsymbol{\alpha}}{\boldsymbol{\sigma}-\boldsymbol{\alpha}^{\prime}}
$$

where $k_{1} \ll k_{2}$, ensuring that no intersections appear between the two surfaces.

2.2. Numerical Implementation of Constitutive Equations. The constitutive equations have been implemented via usermaterial (UMAT) subroutines in ABAQUS/Standard on the basis of incremental deformation approach [42, 49-52].

Firstly, it is assumed that the stress, back-stresses, elastic strain, and plastic strain are obtained as $\boldsymbol{\sigma}^{(n)}, \boldsymbol{\alpha}^{(n)}$, $\boldsymbol{\alpha}^{\prime(n)}, \boldsymbol{\varepsilon}_{e}^{(n)}$, and $\boldsymbol{\varepsilon}_{p}^{(n)}$ at the $n$th step, respectively, as well as a strain increment $\Delta \varepsilon$ is given for the $(n+1)$ th step.

Neglecting the plastic part in the strain increment $\Delta \varepsilon$, the initial value of the stress at the $(n+1)$ th step can be estimated by

$$
\boldsymbol{\sigma}_{\text {initial }}^{(n+1)}=\boldsymbol{\sigma}^{(n)}+D_{e}: \Delta \boldsymbol{\varepsilon},
$$

which is afterwards employed to determine the current stress state of the material:

$$
\text { (a) if } F_{1}\left(\boldsymbol{\sigma}_{\text {initial }}^{(n+1)}, \boldsymbol{\alpha}^{(n)}, k_{1}\right)<0 \text {. }
$$

The stress state is pure elastic. Updating the stress and back-stress inside the initial yield surface gives

$$
\begin{aligned}
\boldsymbol{\sigma}^{(n+1)} & =\boldsymbol{\sigma}_{\text {initial }}^{(n+1)} \\
\boldsymbol{\alpha}^{(n+1)} & =\boldsymbol{\alpha}^{(n)}, \\
\text { (b) else if } F_{1}\left(\boldsymbol{\sigma}_{\text {initial }}^{(n+1)}, \boldsymbol{\alpha}^{(n)}, k_{1}\right) & \geq 0, \\
\text { and } F_{2}\left(\boldsymbol{\sigma}_{\text {initial }}^{(n+1)}, \boldsymbol{\alpha}^{\prime(n)}, k_{2}\right) & <0 .
\end{aligned}
$$

The stress state is mixed elastic-plastic. The renewed stress is reckoned by 


$$
\left.\boldsymbol{\sigma}^{(n+1)}=\boldsymbol{\sigma}^{(n)}+D_{e}:\left(\Delta \boldsymbol{\varepsilon}-\left(1-\frac{\bar{\xi}}{2}\right) \cdot \boldsymbol{\varepsilon}_{p}^{(n)}\right)\right) .
$$

The back-stress update is executed in the following manner:

$$
\boldsymbol{\alpha}^{(n+1)}=\boldsymbol{\alpha}^{(n)}+\Delta \mu \cdot\left(\frac{k_{2}-k_{1}}{k_{1}} \cdot\left(\boldsymbol{\sigma}^{(n)}-\boldsymbol{\alpha}^{(n)}\right)\right),
$$

where $\Delta \mu$ is evaluated through the steps given below:

(i) Adopting the von Mises yield criterion for $F_{1}$ produces

$$
\begin{aligned}
& \frac{1}{2}\left(\left(\Sigma_{x}-\Sigma_{y}\right)^{2}+\left(\Sigma_{y}-\Sigma_{z}\right)^{2}+\left(\Sigma_{z}-\Sigma_{x}\right)^{2}\right) \\
& +3\left(T_{x y}^{2}+T_{y z}^{2}+T_{z x}^{2}\right)=k_{1}^{2},
\end{aligned}
$$

where $\Sigma_{x}, \Sigma_{y}, \Sigma_{z}, T_{x y}, T_{y z}, T_{z x}$ are the stress tensor components and

$$
\begin{aligned}
\Sigma_{x}-\Sigma_{y} & =\left(\boldsymbol{\sigma}_{x}^{(n+1)}-\boldsymbol{\sigma}_{y}^{(n+1)}\right)-\left(\boldsymbol{\alpha}_{x}^{(n)}-\boldsymbol{\alpha}_{y}^{(n)}\right)-\Delta \mu \cdot\left(\Gamma_{x}-\Gamma_{y}\right), \\
\Sigma_{y}-\Sigma_{z} & =\left(\boldsymbol{\sigma}_{y}^{(n+1)}-\boldsymbol{\sigma}_{z}^{(n+1)}\right)-\left(\boldsymbol{\alpha}_{y}^{(n)}-\boldsymbol{\alpha}_{z}^{(n)}\right)-\Delta \mu \cdot\left(\Gamma_{y}-\Gamma_{z}\right), \\
\Sigma_{z}-\Sigma_{x} & =\left(\boldsymbol{\sigma}_{z}^{(n+1)}-\boldsymbol{\sigma}_{x}^{(n+1)}\right)-\left(\boldsymbol{\alpha}_{z}^{(n)}-\boldsymbol{\alpha}_{x}^{(n)}\right)-\Delta \mu \cdot\left(\Gamma_{z}-\Gamma_{x}\right), \\
T_{x y} & =\boldsymbol{\sigma}_{x y}^{(n+1)}-\boldsymbol{\alpha}_{x y}^{(n)}-\Delta \mu \cdot \Gamma_{x y}, \\
T_{y z} & =\boldsymbol{\sigma}_{y z}^{(n+1)}-\boldsymbol{\alpha}_{y z}^{(n)}-\Delta \mu \cdot \Gamma_{y z} \\
T_{z x} & =\boldsymbol{\sigma}_{z x}^{(n+1)}-\boldsymbol{\alpha}_{z x}^{(n)}-\Delta \mu \cdot \Gamma_{z x} .
\end{aligned}
$$

where

$$
\Gamma=\frac{k_{2}-k_{1}}{k_{1}} \cdot\left(\boldsymbol{\sigma}^{(n)}-\boldsymbol{\alpha}^{(n)}\right)
$$

(ii) Substituting Equations (16) and (17) in Equation (15) yields

$$
a \Delta \mu^{2}+b \Delta \mu+c=0
$$

where

$$
\begin{aligned}
a= & \left(\left(\Gamma_{x}-\Gamma_{y}\right)^{2}+\left(\Gamma_{y}-\Gamma_{z}\right)^{2}+\left(\Gamma_{z}-\Gamma_{x}\right)^{2}\right) \\
& +6\left(\Gamma_{x y}^{2}+\Gamma_{y z}^{2}+\Gamma_{z x}^{2}\right), \\
b= & -2\left(\left(\Gamma_{x}-\Gamma_{y}\right)\left(\left(\boldsymbol{\sigma}_{x}^{(n+1)}-\boldsymbol{\sigma}_{y}^{(n+1)}\right)-\left(\boldsymbol{\alpha}_{x}^{(n)}-\boldsymbol{\alpha}_{y}^{(n)}\right)\right)\right. \\
& +\left(\Gamma_{y}-\Gamma_{z}\right)\left(\left(\boldsymbol{\sigma}_{y}^{(n+1)}-\boldsymbol{\sigma}_{z}^{(n+1)}\right)-\left(\boldsymbol{\alpha}_{y}^{(n)}-\boldsymbol{\alpha}_{z}^{(n)}\right)\right) \\
& \left.+\left(\Gamma_{z}-\Gamma_{x}\right)\left(\left(\boldsymbol{\sigma}_{z}^{(n+1)}-\boldsymbol{\sigma}_{x}^{(n+1)}\right)-\left(\boldsymbol{\alpha}_{z}^{(n)}-\boldsymbol{\alpha}_{x}^{(n)}\right)\right)\right) \\
& -12\left(\Gamma_{x y}\left(\boldsymbol{\sigma}_{x y}^{(n+1)}-\boldsymbol{\alpha}_{x y}^{(n)}\right)+\Gamma_{y z}\left(\boldsymbol{\sigma}_{y z}^{(n+1)}-\boldsymbol{\alpha}_{y z}^{(n)}\right)\right. \\
& \left.+\Gamma_{z x}\left(\boldsymbol{\sigma}_{z x}^{(n+1)}-\boldsymbol{\alpha}_{z x}^{(n)}\right)\right)
\end{aligned}
$$

$$
\begin{aligned}
c= & \left(\left(\left(\boldsymbol{\sigma}_{x}^{(n+1)}-\boldsymbol{\sigma}_{y}^{(n+1)}\right)-\left(\boldsymbol{\alpha}_{x}^{(n)}-\boldsymbol{\alpha}_{y}^{(n)}\right)\right)^{2}\right. \\
& +\left(\left(\boldsymbol{\sigma}_{y}^{(n+1)}-\boldsymbol{\sigma}_{z}^{(n+1)}\right)-\left(\boldsymbol{\alpha}_{y}^{(n)}-\boldsymbol{\alpha}_{z}^{(n)}\right)\right)^{2} \\
& \left.+\left(\left(\boldsymbol{\sigma}_{z}^{(n+1)}-\boldsymbol{\sigma}_{x}^{(n+1)}\right)-\left(\boldsymbol{\alpha}_{z}^{(n)}-\boldsymbol{\alpha}_{x}^{(n)}\right)\right)^{2}\right) \\
& +6\left(\left(\boldsymbol{\sigma}_{x y}^{(n+1)}-\boldsymbol{\alpha}_{x y}^{(n)}\right)^{2}+\left(\boldsymbol{\sigma}_{y z}^{(n+1)}-\boldsymbol{\alpha}_{y z}^{(n)}\right)^{2}\right. \\
& \left.+\left(\boldsymbol{\sigma}_{z x}^{(n+1)}-\boldsymbol{\alpha}_{z x}^{(n)}\right)^{2}\right)-2 k_{1}^{2},
\end{aligned}
$$

$$
\Delta \mu=\frac{-b+\sqrt{b^{2}-4 a c}}{2 a} .
$$

The updated back-stress $\boldsymbol{\alpha}^{(n+1)}$ is thus obtained by substituting Equation (20) in Equation (14).

$$
\text { (c) else if } F_{2}\left(\boldsymbol{\sigma}_{\text {initial }}^{(n+1)}, \boldsymbol{\alpha}^{\prime(n)}, k_{2}\right)>0 \text {. }
$$

The stress is in the complete plastic state. The stress renewal is achieved by

$$
\boldsymbol{\sigma}^{(n+1)}=\boldsymbol{\sigma}^{(n)}+D_{e}:\left(\Delta \boldsymbol{\varepsilon}-\boldsymbol{\varepsilon}_{p}^{(n)}\right)
$$

Thereby the updated back-stress and size of $F_{2}$ are, respectively, expressed as

$$
\begin{aligned}
\boldsymbol{\alpha}^{\prime(n+1)} & =\sum_{i=1}^{3} \eta_{i}^{(n+1)}\left(\boldsymbol{\alpha}_{i}^{\prime(n)}+\frac{2}{3} C_{i} \Delta \boldsymbol{\varepsilon}_{p}^{(n+1)}\right), \\
\eta_{i}^{(n+1)} & =\frac{1}{1+a_{i} \Delta \overline{\boldsymbol{\varepsilon}}_{p}^{(n+1)}}, \quad 0<\eta_{i}^{(n+1)} \leq 1, \\
k_{2}^{(n+1)} & =Q\left(1-\exp \left(-b \overline{\boldsymbol{\varepsilon}}_{p}^{(n+1)}\right)\right) .
\end{aligned}
$$

The update in the size of $F_{1}$ is subsequently made available from

$$
k_{1}^{(n+1)}=k_{2}^{(n+1)} \frac{\boldsymbol{\sigma}^{(n+1)}-\boldsymbol{\alpha}^{(n)}}{\boldsymbol{\sigma}^{(n+1)}-\boldsymbol{\alpha}^{(n+1)}} .
$$

Figure 1 presents the schematic diagram of the constitutive model with a consideration of grained inhomogeneity.

2.3. Parametric Values of the Constitutive Model. The $250 \mu \mathrm{m}$ thick 304 stainless steel specimens with different average grain sizes have been utilised to assess the performance of the developed constitutive model. The mechanical properties as well as the weighted heterogeneity coefficient of each specimen have been determined by miniature tensile tests and microhardness tests, respectively. Note that the basic principles and practical procedures of both types of tests can be referred to Ref. [5]. Table 1 lists the average values of the properties identified for the experimental materials.

The parametric values in regard to the Chaboche kinematic hardening model involved in the constitutive modelling were adopted from Badnava et al.'s study [46] and are enumerated in Table 2. Note that in this study, the Chaboche model was utilised to describe the nonlinear 


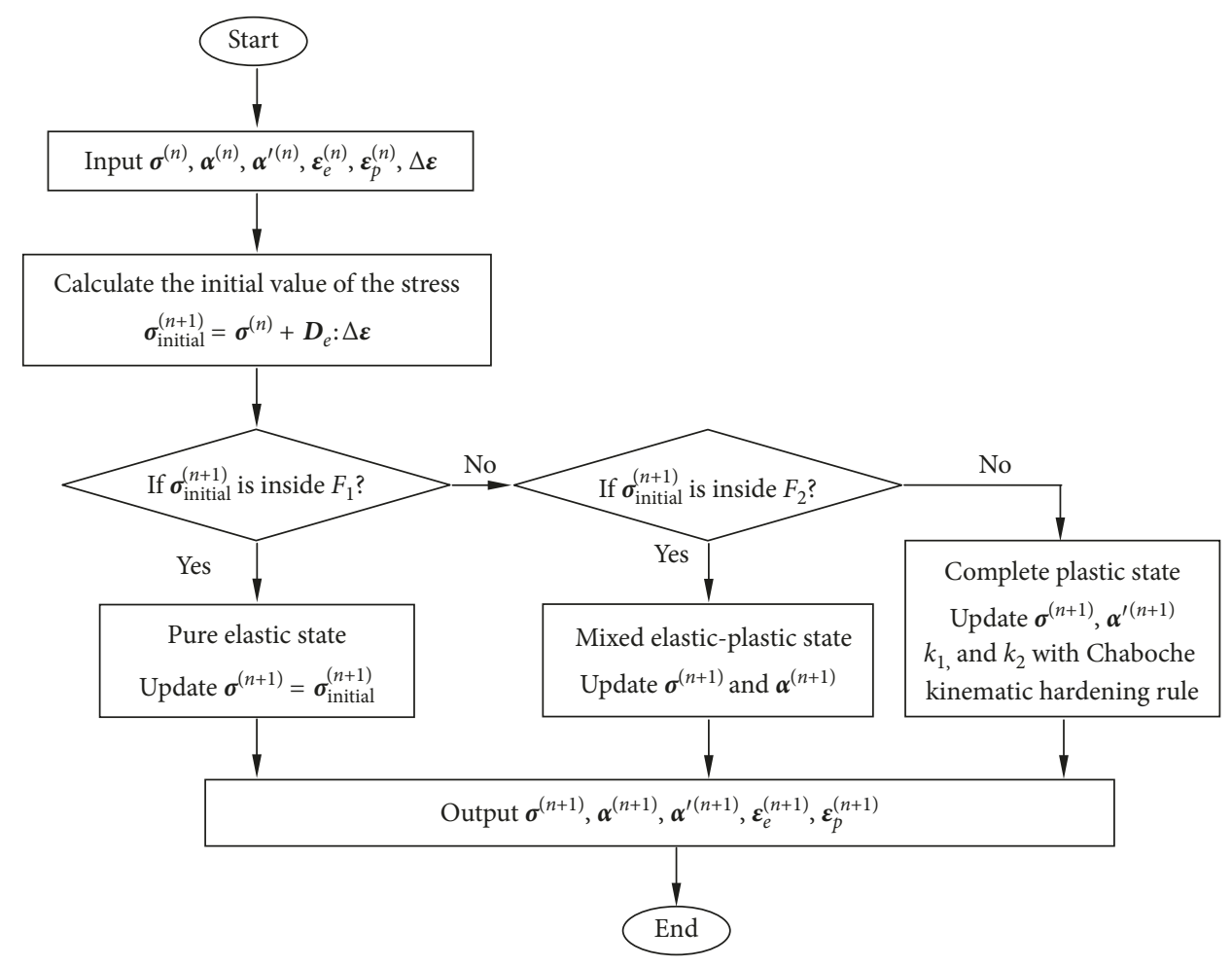

Figure 1: Schematic diagram of the constitutive model with consideration of grained inhomogeneity.

TABLE 1: Average values of properties of 304 stainless steel specimens with different average grain sizes.

\begin{tabular}{|c|c|c|c|c|c|c|}
\hline \multirow{2}{*}{ Property } & \multicolumn{6}{|c|}{ Approximate average grain size $(\mu \mathrm{m})$} \\
\hline & $22\left(S_{1}\right)$ & $29\left(\mathrm{~S}_{2}\right)$ & $40\left(S_{3}\right)$ & $53\left(S_{4}\right)$ & $61\left(S_{5}\right)$ & $74\left(S_{6}\right)$ \\
\hline Density $\rho\left(\mathrm{kg} / \mathrm{m}^{3}\right)$ & 8000 & 8000 & 8000 & 8000 & 8000 & 8000 \\
\hline Elastic modulus $E(\mathrm{MPa})$ & 177890 & 169893 & 162570 & 156090 & 148881 & 140803 \\
\hline Poisson's ratio $v$ & 0.29 & 0.29 & 0.29 & 0.29 & 0.29 & 0.29 \\
\hline Yield strength at $0.2 \%$ offset $\sigma_{0.2}(\mathrm{MPa})$ & 356 & 340 & 325 & 312 & 297 & 282 \\
\hline Ultimate tensile strength $\sigma_{\mathrm{u}}(\mathrm{MPa})$ & 778 & 745 & 721 & 700 & 684 & 655 \\
\hline Elongation at failure $\varepsilon_{\mathrm{f}}(\%)$ & 65 & 61 & 58 & 56 & 55 & 52 \\
\hline Weighted heterogeneity coefficient $\bar{\xi}$ & 1.012 & 1.024 & 1.031 & 1.024 & 1.026 & 1.021 \\
\hline
\end{tabular}

TABLe 2: Parametric values of Chaboche kinematic hardening model for 304 stainless steel specimens [46].

\begin{tabular}{cccccccc}
\hline$b$ & $Q$ & $C_{1}(\mathrm{MPa})$ & $a_{1}$ & $C_{2}(\mathrm{MPa})$ & $a_{2}$ & $C_{3}(\mathrm{MPa})$ & $a_{3}$ \\
\hline 15 & 215 & 63000 & 8950 & 41000 & 500 & 1650 & 6 \\
\hline
\end{tabular}

kinematic hardening behaviour of the material with grains that had entered plastic deformation regime. As the microinhomogeneity effect induced by different stress states of individual grains "disappears" at this stage, the material was considered uniform and treated equivalently with a development of plastic deformation at the macroscale. Therefore, macroscopic Chaboche model parameters have been adopted for numerical calculation of back-stress during plastic deformation. Another point worthy of note is that the six groups of materials were presumed to share the same parametric values involved in the Chaboche kinematic hardening model to reproduce the macroscopic behaviour in the regime of plastic activity; nevertheless, they were assigned with various elastic moduli and dissimilar weighted heterogeneity coefficients to distinguish them from one another for the time when they were subjected to the stress states of pure elastic and mixed elastic-plastic at the microscale, respectively.

2.4. Validation of the Constitutive Model. In the developed constitutive model, size effects were principally integrated into the mixed elastic-plastic regime by introducing a weighted heterogeneity coefficient to specify the proportions of elastically and plastically deformed grains, respectively. As can be read off from Table 1, variation in this 
particular coefficient reflects the change in microstructure characterised by average grain size. The validation of the developed constitutive model that involves cross-scale parametric values has been fulfilled as per the simulated and experimental stress-strain curves, and the comparison in-between.

Figure 2 displays the stress-strain curves predicted by the elastic-plastic mixed-state model and the stress-strain data points obtained from miniature tensile tests for 304 stainless steel specimens $S_{1}-S_{6}$ with average grain size of $22-74 \mu \mathrm{m}$. Generally, the ductility, the yield stress, and the ultimate tensile stress all increase with the decrease of the average grain size because of the enhancement of the grain boundary strengthening effect as well as the change of the fracture mechanism [53]. It can be observed from Figure 2 that the predicted curves almost coincide with the experimental points except for several small deviations, which indicates that the developed constitutive model is valid and can be employed for the numerical prediction of springback behaviour in microflexible rolling.

\section{Numerical Simulations and Experiments of Microflexible Rolling}

3.1. Numerical Simulations of Microflexible Rolling. The halfsymmetric 3D microflexible rolling finite element model has been established using the commercial FEA software package, ABAQUS/CAE. As exhibited in Figure 3, in order to achieve higher computational efficiency with less computational resource, the inner portion of the roll body has been removed as only its outer surface will be in contact with the material during the real forming process [54]. The basic geometric parameters of the FE model are as follows: outer diameter of the roll $D=25 \mathrm{~mm}$, length of the roll $B=35 \mathrm{~mm}$, length of the strip $L=40 \mathrm{~mm}$, width of the strip $b=10 \mathrm{~mm}$, and initial thickness of the strip $H=250 \mu \mathrm{m}$.

One contact pair was set up in the finite element model, namely, the outer surface of the roll body and the top surface of the strip, which was defined as frictional interface adopting a friction coefficient of 0.15 , as well as applying the finite sliding formulation and surface-to-surface discretisation approach to obtain a stress accuracy improvement $[5,54]$.

Three phases were involved in the simulation of microflexible rolling process, to wit, $5 \%$ thickness reduction for the first rolling phase to form the thicker area, which was followed by the thickness transition area wherein thickness reduction increased swiftly from 5 to $10 \%$, and then the third rolling phase with $10 \%$ thickness reduction to form the thinner area (i.e., the amount of thickness reduction is $12.5 \mu \mathrm{m}$ for thicker area while $25 \mu \mathrm{m}$ for thinner area) [5].

For comparison purposes, both the elastic-plastic mixedstate (EPMS) and multilinear isotropic hardening (MISO) models have been employed to describe the constitutive behaviour of the material and these simulation results are labelled as "Category 1" (obtained utilising the EPMS model) and "Category 2" (obtained utilising the MISO model), respectively.

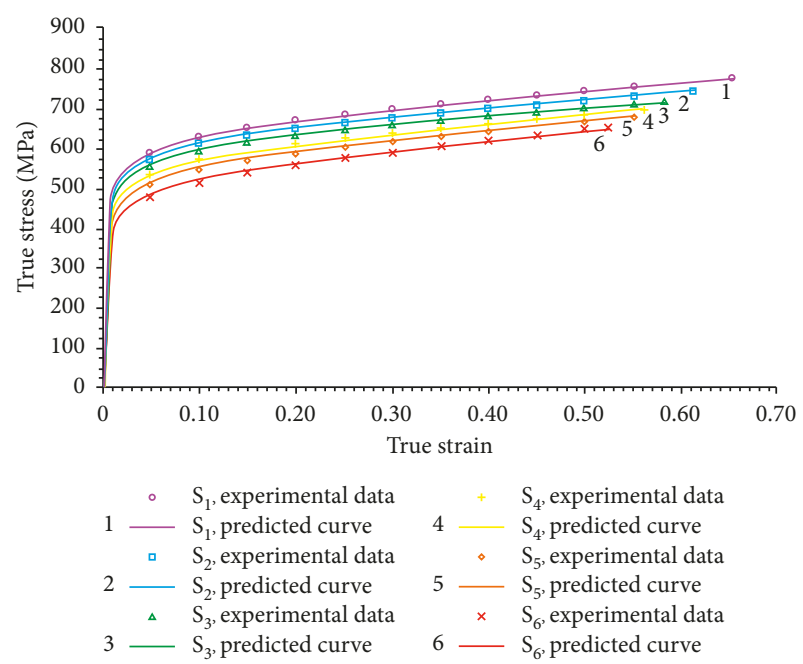

Figure 2: Comparison of elastic-plastic mixed-state model predictions and experimental data for 304 stainless steel specimens $\mathrm{S}_{1}-\mathrm{S}_{6}$.

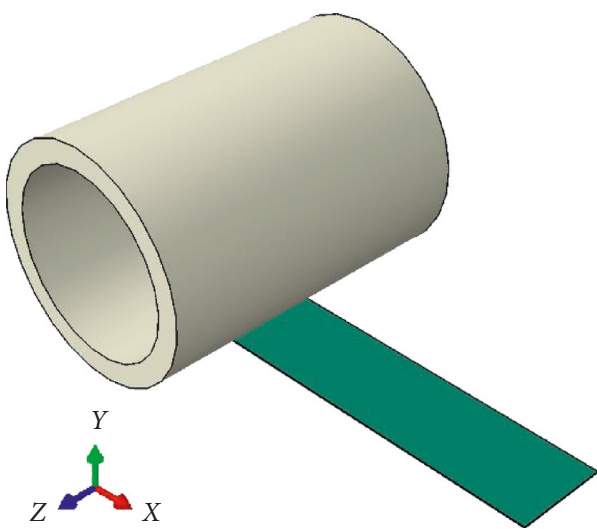

FIgURE 3: Symmetric top half of 3D finite element model of microflexible rolling.

Furthermore, the 3D Voronoi tessellation technique has been exploited to further visualise the inhomogeneous microstructure of the workpiece which comprises grains that have dissimilar properties assigned to them. The basic concept of this method can be understood by distributing a set of Voronoi sites randomly within the workpiece volume, which partition the space into regions such that all locations within one certain region are closer to its generating site than to others [55]. This process was realised with the aid of MATLAB, which created a script file to help accomplish the Voronoi modelling in ABAQUS/CAE. Figure 4 displays an overview of the established 3D Voronoi tessellation in the mimicked 304 stainless steel strips, where different colours reflect different grain properties that were sorted and quantified with respect to the results produced by both the microhardness and miniature tensile tests [5]. Note that the MISO model has been adopted to represent the constitutive relations for each grain and the simulation results obtained using such a combined modelling approach (named VMISO model) are labelled as "Category 3". 


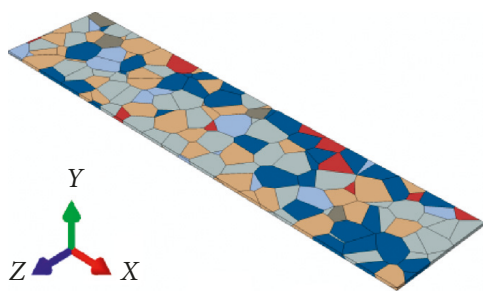

(a)

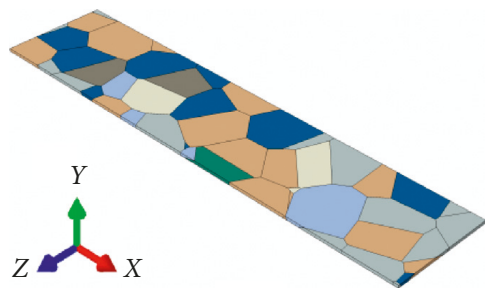

(c)

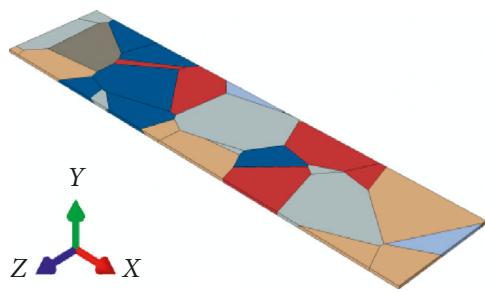

(e)

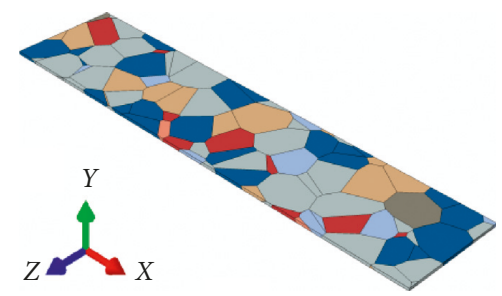

(b)

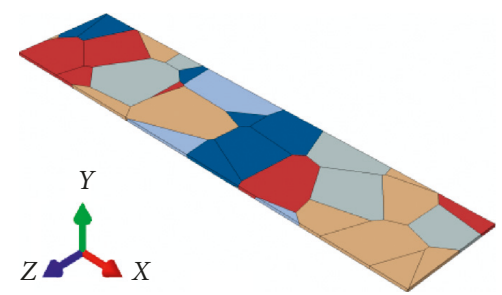

(d)

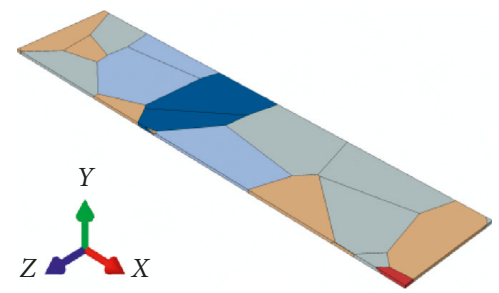

(f)

FIGURE 4: Overview of established 3D Voronoi tessellation in the mimicked 304 stainless steel strips: (a) $S_{1}$; (b) $S_{2}$; (c) $S_{3}$; (d) $S_{4}$; (e) $S_{5}$; (f) $S_{6}$.

3.2. Physical Experiments of Microflexible Rolling. Physical experiments have been set up under the FEA simulation conditions and conducted on the self-developed prototype microflexible rolling mill. In addition, all the specimens were rolled at a speed of $20 \mathrm{~cm} / \mathrm{min}$ and without lubrication [5]. Exemplarily, Figure 5 shows the overviews and magnified profiles in thickness transition areas of the microflexible rolled 304 stainless steel specimens $S_{1}-S_{6}$, in which these areas were marked red, allowing them to be located easily under the microscope.

Table 3 lists the experimental results for the microflexible rolled 304 stainless steel specimens for both reductions of 5 and $10 \%$, where the thickness directional springback of the specimen was estimated by the final thickness minus the average value of the actual roll gap. Note that the measurement of the final thickness was taken using a micrometer and was repeated at 10 different locations in the test area. These results were afterwards averaged to ensure an accurate representation of workpiece thickness after rolling [5].

\section{Simulation Results and Discussion}

Taking 304 stainless steel specimens $S_{1}$ as an example, Figures 6-8 illustrate the distribution of effective stress in the rolled workpiece using the aforementioned three categories of constitutive/numerical models, respectively.

As can be observed from these figures, the effective stress distributions obtained from both the EPMS and MISO models generally exhibit a symmetric pattern with a smooth, gradual stress transition within the workpieces (for instance, see enlarged areas in Figures 6 and 7, respectively), whereas the VMISO model has introduced large inhomogeneities in the form of sudden changes in the effective stress distribution (for instance, see enlarged areas in Figure 8) and this irregularity can be accounted for by the different mechanical response of each grain to the external stress, which means some grains have slipped into the plastic state while others still remain in an elastic state with respect to the forces applied through the rolls; nonetheless, smaller effective stress was generated at the centre than at both edges of the workpiece regardless of what type of constitutive/numerical model had been applied, mainly because the maximum deflection of the roll occurred at its centre, consequently exerting less compression at the centre of the workpiece [5].

This study has emphasised the investigation of thickness directional springback as it determines the dimensional accuracy as well as the supplementary amount of the reduction in microflexible rolling. The simulation result of thickness directional springback was calculated as the average distance between the upper and lower surface nodes of the workpiece after leaving the roll bite minus the minimum average distance between those in the roll bite. Four sets of data were collected and arranged, and each set was further sorted into six groups of fifteen specimens each according to the average grain sizes summarised in Table 1, and specimens $S_{1}-S_{6}$ were representative selections for they individually had the middle values in each group of one data set [5]. 

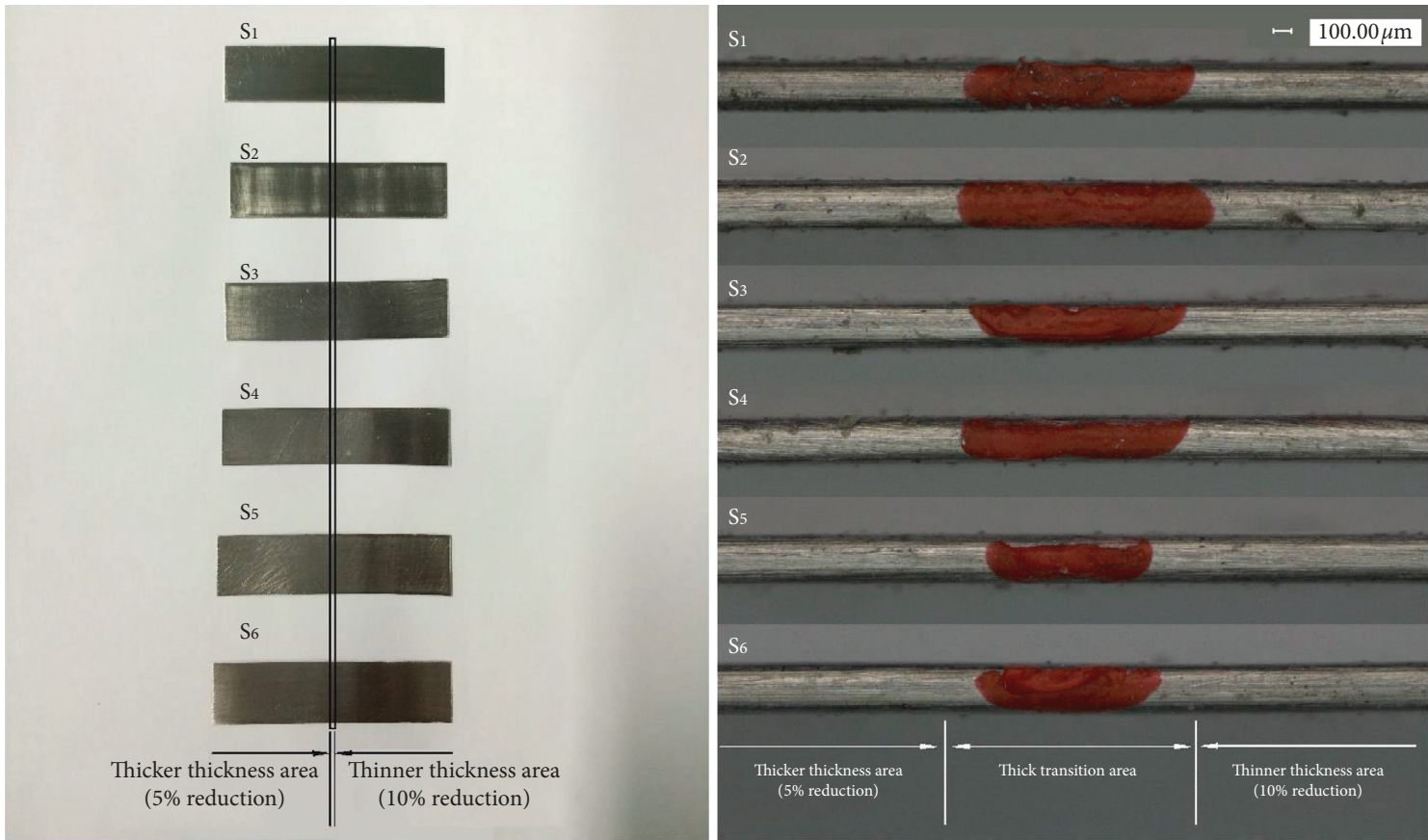

Figure 5: Overviews and magnified profiles in thickness transition areas of the microflexible rolled 304 stainless steel specimens $S_{1}-S_{6}$.

TABLe 3: Experimental results for the microflexible rolled 304 stainless steel specimens.

\begin{tabular}{|c|c|c|c|c|c|c|}
\hline \multirow{2}{*}{ Test index } & \multicolumn{6}{|c|}{ Specimen no. } \\
\hline & $\mathrm{S}_{1}$ & $\mathrm{~S}_{2}$ & $\mathrm{~S}_{3}$ & $\mathrm{~S}_{4}$ & $\mathrm{~S}_{5}$ & $\mathrm{~S}_{6}$ \\
\hline \multicolumn{7}{|l|}{$5 \%$ reduction } \\
\hline Average value of actual roll gap $(\mu \mathrm{m})$ & 235.468 & 235.671 & 235.252 & 235.225 & 235.446 & 235.469 \\
\hline Final thickness $(\mu \mathrm{m})$ & 238.100 & 238.200 & 237.900 & 237.800 & 238.100 & 238.300 \\
\hline Thickness directional springback $(\mu \mathrm{m})$ & 2.632 & 2.529 & 2.648 & 2.575 & 2.654 & 2.831 \\
\hline \multicolumn{7}{|l|}{$10 \%$ reduction } \\
\hline Average value of actual roll gap $(\mu \mathrm{m})$ & 221.403 & 221.222 & 221.116 & 221.497 & 221.607 & 221.285 \\
\hline Final thickness $(\mu \mathrm{m})$ & 225.900 & 225.700 & 225.800 & 226.100 & 226.400 & 226.300 \\
\hline Thickness directional springback $(\mu \mathrm{m})$ & 4.497 & 4.478 & 4.684 & 4.603 & 4.793 & 5.015 \\
\hline
\end{tabular}
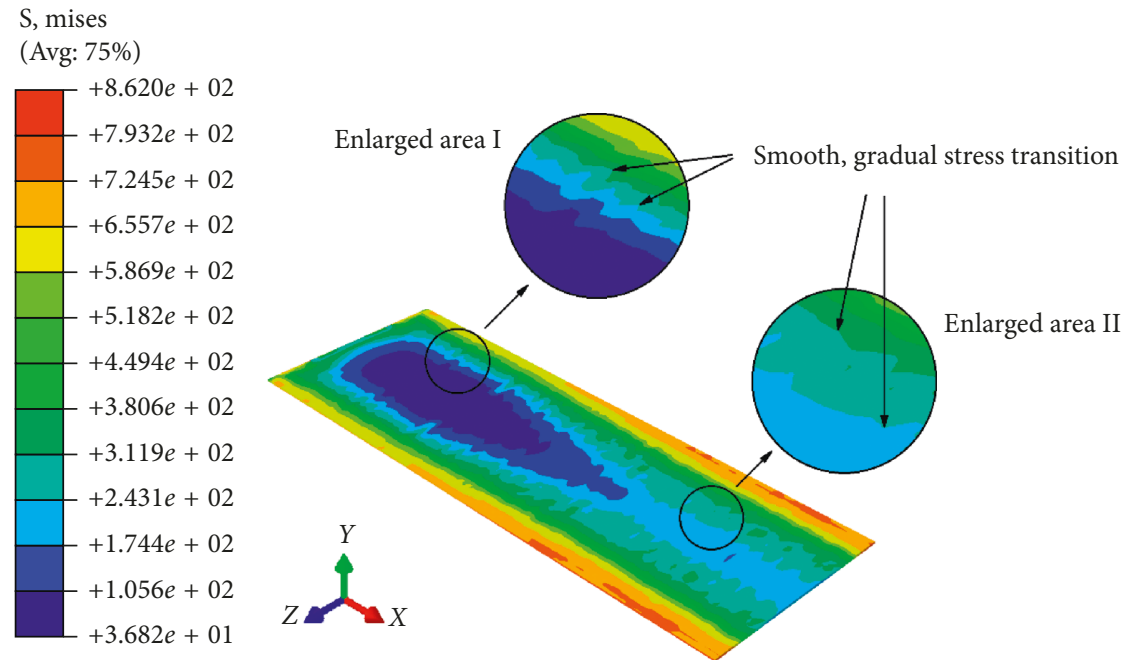

FIGURE 6: Distribution of effective stress in the microflexible rolled 304 stainless steel specimen $\mathrm{S}_{1}$ utilising the EPMS model. Enlarged area I: thicker thickness area with 5\% reduction; enlarged area II: thinner thickness area with $10 \%$ reduction. 

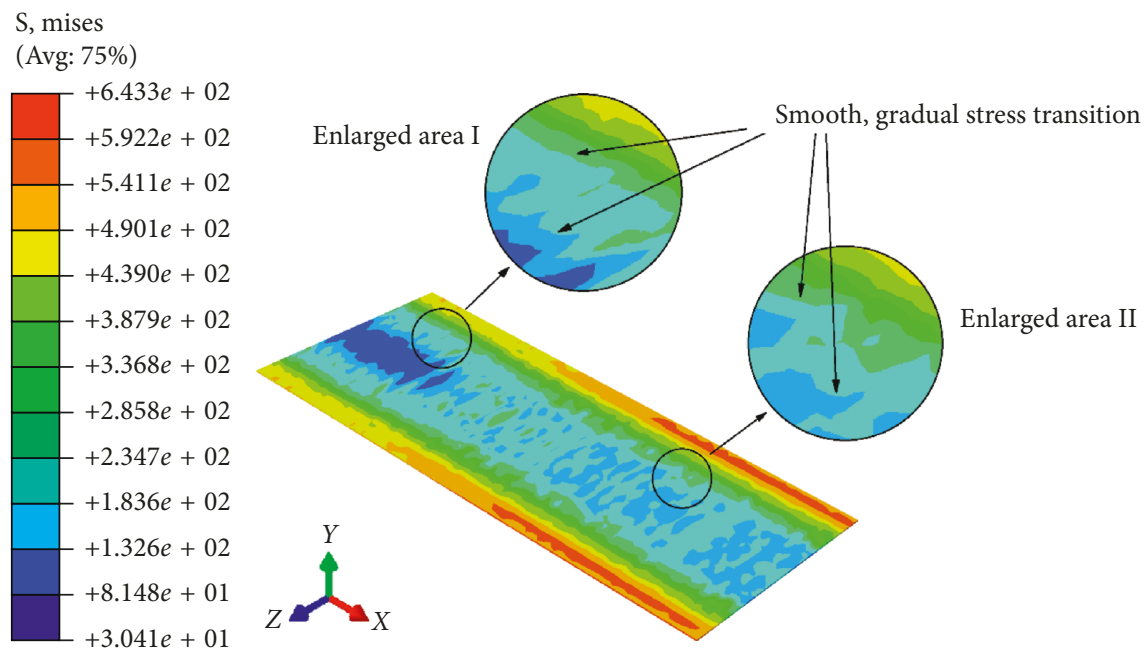

FIGURE 7: Distribution of effective stress in the microflexible rolled 304 stainless steel specimen $\mathrm{S}_{1}$ utilising the MISO model. Enlarged area I: thicker thickness area with 5\% reduction; enlarged area II: thinner thickness area with $10 \%$ reduction.
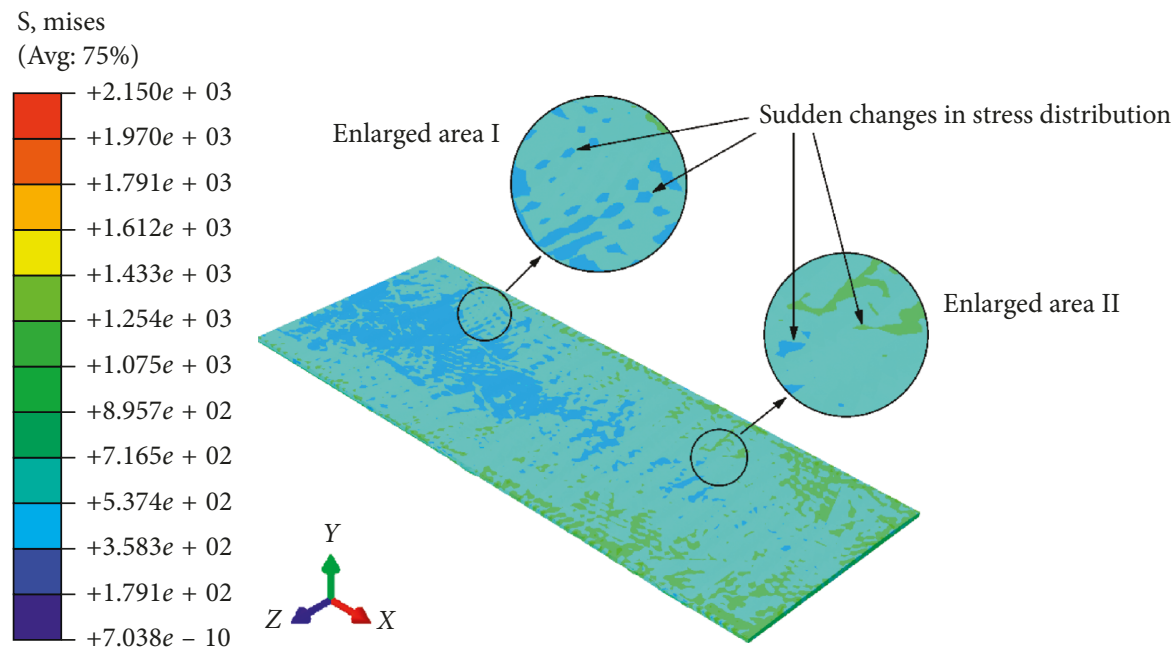

FIgURE 8: Distribution of effective stress in the microflexible rolled 304 stainless steel specimen $\mathrm{S}_{1}$ utilising the VMISO model. Enlarged area I: thicker thickness area with 5\% reduction; enlarged area II: thinner thickness area with $10 \%$ reduction.

Figure 9 depicts the correlation between the thickness directional springback and average grain size such that the former basically exhibits fluctuations with the latter, ascribable to the variability of the ratio of average rolling force to elastic modulus of the workpiece, which nevertheless stays approximately $4.50 \mu \mathrm{m}$ at the reduction of $10 \%$, nearly twice as much as that of around $2.50 \mu \mathrm{m}$ at the reduction of $5 \%$. Another point should be mentioned here is that only one type of grain size was obtained in each group, and a small offset value was deliberately given to set four types of data apart from each other so that the scatter of thickness directional springback can be seen obviously in this figure, which expands as the impact of each single grain becomes more pronounced with the decreasing number, as a consequence of the increasing size of grains within a constant strip thickness for each data set [5].
Additionally, it is observed from Figure 9 that the Category 2 of MISO model provides generally less satisfactory predictions of thickness directional springback at different average grain sizes, as the nonlinear loading involving the transition of the stress state is not likely to be represented adequately despite a continuous piecewise linear approximation to the flow curve of the material, while the Category 1 of EPMS model exhibits a better agreement with the measured data as it has captured the Bauschinger effect, traced the evolution of the back-stress, as well as incorporated the mixed elastic-plastic stress state aroused by grained heterogeneity. Likewise, in spite of making use of the Category 3 of VMISO model for better mimicking of morphologies of grains of various average sizes and further improvement in prediction accuracy, it cannot offer the same predictive capacity as the Category 1 of EPMS model does owing to the 


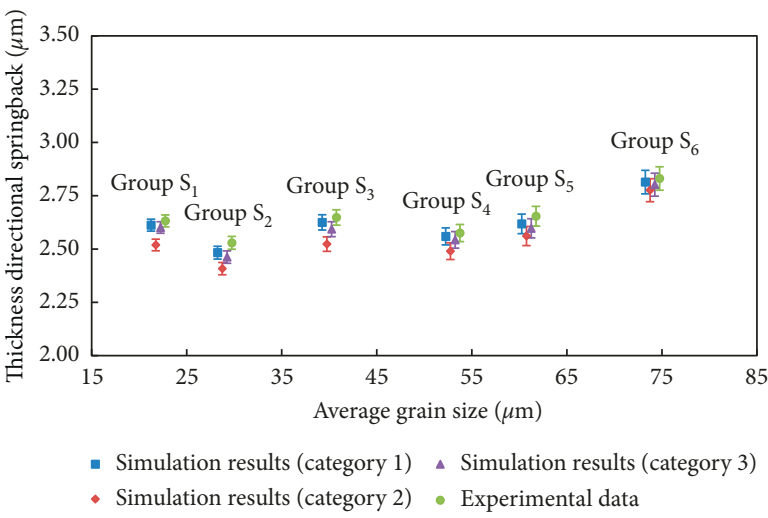

(a)

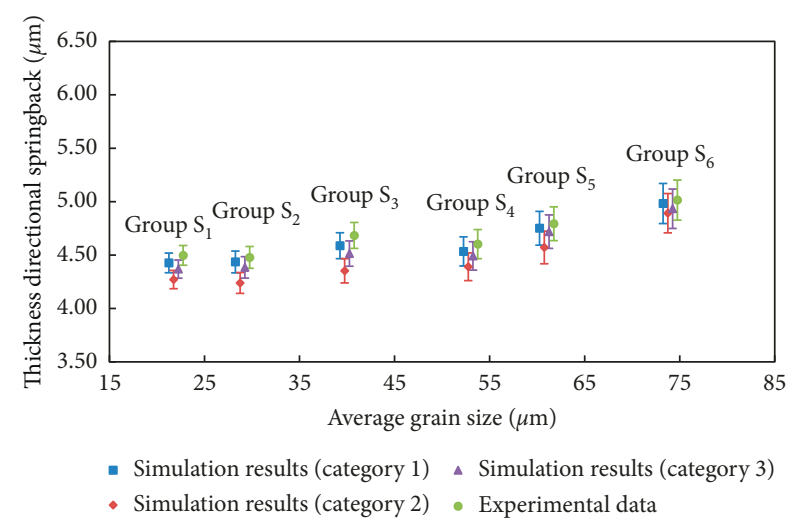

(b)

Figure 9: Correlation between thickness directional springback and average grain size for Groups $S_{1}-S_{6}$ : (a) 5\% reduction; (b) $10 \%$ reduction.

TABLE 4: Comparison between numerical results of thickness directional springback for 304 stainless steel specimens based on different constitutive/numerical models.

\begin{tabular}{|c|c|c|c|c|c|c|}
\hline \multirow{2}{*}{ Thickness directional springback } & \multicolumn{6}{|c|}{ Specimen no. } \\
\hline & $\mathrm{S}_{1}$ & $\mathrm{~S}_{2}$ & $\mathrm{~S}_{3}$ & $\mathrm{~S}_{4}$ & $\mathrm{~S}_{5}$ & $\mathrm{~S}_{6}$ \\
\hline \multicolumn{7}{|l|}{$5 \%$ reduction } \\
\hline EPMS model $(\mu \mathrm{m})$ & 2.612 & 2.483 & 2.625 & 2.559 & 2.618 & 2.814 \\
\hline MISO model $(\mu \mathrm{m})$ & 2.519 & 2.408 & 2.523 & 2.490 & 2.561 & 2.776 \\
\hline VMISO model $(\mu \mathrm{m})$ & 2.601 & 2.462 & 2.593 & 2.543 & 2.597 & 2.802 \\
\hline Experimental $(\mu \mathrm{m})$ & 2.632 & 2.529 & 2.648 & 2.575 & 2.654 & 2.831 \\
\hline Error-I (\%) & 0.76 & 1.82 & 0.87 & 0.62 & 1.36 & 0.60 \\
\hline Error-II (\%) & 4.29 & 4.78 & 4.72 & 3.30 & 3.50 & 1.94 \\
\hline Error-III (\%) & 1.18 & 2.65 & 2.08 & 1.24 & 2.15 & 1.02 \\
\hline \multicolumn{7}{|l|}{$10 \%$ reduction } \\
\hline EPMS model $(\mu \mathrm{m})$ & 4.427 & 4.436 & 4.588 & 4.534 & 4.751 & 4.983 \\
\hline MISO model $(\mu \mathrm{m})$ & 4.271 & 4.239 & 4.353 & 4.391 & 4.572 & 4.892 \\
\hline VMISO model $(\mu \mathrm{m})$ & 4.369 & 4.385 & 4.514 & 4.492 & 4.719 & 4.934 \\
\hline Experimental $(\mu \mathrm{m})$ & 4.497 & 4.478 & 4.684 & 4.603 & 4.793 & 5.015 \\
\hline Error-I (\%) & 1.56 & 0.94 & 2.05 & 1.50 & 0.88 & 0.64 \\
\hline Error-II (\%) & 5.03 & 5.34 & 7.07 & 4.61 & 4.61 & 2.45 \\
\hline Error-III (\%) & 2.85 & 2.08 & 3.63 & 2.41 & 1.54 & 1.62 \\
\hline
\end{tabular}

multilinear isotropic hardening law employed for each individual grain.

The errors are respectively evaluated as

$$
\begin{gathered}
\text { Error }-\mathrm{I}=\frac{\mid \text { EPMS model }- \text { Experimental } \mid}{\text { Experimental }} \times 100 \%, \\
\text { Error }-\mathrm{II}=\frac{\mid \text { MISO model }- \text { Experimental } \mid}{\text { Experimental }} \times 100 \%, \\
\text { Error }- \text { III }=\frac{\mid \text { VMISO model }- \text { Experimental } \mid}{\text { Experimental }} \times 100 \%
\end{gathered}
$$

Finally, Table 4 illustrates a quantitative comparison of the thickness directional springback utilising the newly established EPMS model together with the conventional MISO model and the VMISO model containing a Voronoi structure involved in the workpiece. According to the calculated errors, the EPMS model has the capacity to provide for an almost $45 \%$ increase in the numerical accuracy compared with the VMISO model and an even larger increase of approximately $74 \%$ compared with the MISO model, which proves its feasibility and demonstrates its better performance on the quantitative prediction of the thickness directional springback in microflexible rolling.

\section{Conclusions}

This study looks into the springback behaviour in microflexible rolling of thin crystalline metal strips with varying longitudinal thickness by means of a combined numerical and experimental approach. The following conclusions can be drawn from this study: 
(i) Constitutive modelling in view of the Chaboche hardening model is conducted to account for the evolution of the back-stress under complicated loading patterns as well as the grain size and grained inhomogeneity effects owing to the decreasing specimen size.

(ii) The novel model is implemented in ABAQUS/ Standard by using user-material (UMAT) subroutines based on an incremental deformation approach to predict the stress-strain curves for 304 stainless steel specimens over a range of average grain sizes. The coincidence between model predictions and experimental data demonstrates the correctness of the developed constitutive model.

(iii) This model is further adopted to quantitatively evaluate the thickness directional springback during microflexible rolling of $250 \mu \mathrm{m}$ thick 304 stainless steel strips with reduction of 5 to $10 \%$. The simulation results are compared with the experimental data with an acceptable error of approximately $1.13 \%$, which also serves as the verification and validation of the developed model.

(iv) The newly established EPMS model significantly improves the springback prediction in microflexible rolling by capturing the Bauschinger effect and tracing the evolution of the back-stress with consideration of grained inhomogeneity, which increases the prediction accuracy by roughly $74 \%$ as compared with the conventional MISO model and by nearly $45 \%$ as compared with the VMISO model with a Voronoi structure constructed in the workpiece.

(v) Quantitative analysis of the variation of thickness directional springback with average grain size is conducted with respect to both reductions for four types of data, and the scatter effect affiliated with the properties of each individual grain is qualitatively estimated in relation to the average grain size.

\section{Data Availability}

The data used to support the findings of this study are included within the article.

\section{Conflicts of Interest}

The authors declare that there are no conflicts of interests.

\section{Acknowledgments}

The authors would like to express their deepest gratitude to University of Wollongong, Australian Research Council (FT120100432).

\section{References}

[1] Z. Y. Jiang and A. K. Tieu, "A simulation of three-dimensional metal forming processes by rigid plastic finite element method," Journal of Materials Processing Technology, vol. 112, no. 1, pp. 144-155, 2001.

[2] C. Lu, A. K. Tieu, and Z. Y. Jiang, "Modelling of the inlet zone in the mixed lubrication situation of cold strip rolling," Journal of Materials Processing Technology, vol. 140, pp. 569-575, 2003.

[3] F. J. Qu, H. B. Xie, and Z. Y. Jiang, "Finite element method analysis of surface roughness transfer in micro flexible rolling," MATEC Web of Conferences, vol. 80, article 04002, 2016.

[4] F. J. Qu, Z. Y. Jiang, and H. N. Lu, "Effect of mesh on springback in 3D finite element analysis of flexible microrolling," Journal of Applied Mathematics, vol. 2015, Article ID 424131, 7 pages, 2015.

[5] F. J. Qu, Z. Y. Jiang, D. B. Wei, Q. Q. Chen, and H. N. Lu, "Study of micro flexible rolling based on grained inhomogeneity," International Journal of Mechanical Sciences, vol. 123, pp. 324-339, 2017.

[6] F. J. Qu, Z. Y. Jiang, and H. N. Lu, "Analysis of micro flexible rolling with consideration of material heterogeneity," International Journal of Mechanical Sciences, vol. 105, pp. 182-190, 2016.

[7] S. B. Chikalthankar, G. D. Belurkar, and V. M. Nandedkar, "Factors affecting on springback in sheet metal bending: a review," International Journal of Engineering and Advanced Technology, vol. 3, no. 4, pp. 247-251, 2014.

[8] A. D. Anggono, W. A. Siswanto, and B. Omar, "Algorithm development and application of spring back compensation for sheet metal forming," Research Journal of Applied Sciences, Engineering and Technology, vol. 4, no. 14, pp. 2036-2045, 2012.

[9] J. Wang, S. Verma, R. Alexander, and J. T. Gau, "Springback control of sheet metal air bending process," Journal of Manufacturing Processes, vol. 10, pp. 21-27, 2008.

[10] A. Gisario, M. Barletta, C. Conti, and S. Guarino, "Springback control in sheet metal bending by laser-assisted bending: experimental analysis, empirical and neural network modelling," Optics and Lasers in Engineering, vol. 49, pp. 13721383, 2011.

[11] W. I. Hameed and K. A. Mohamad, "Strip thickness control of cold rolling mill with roll eccentricity compensation by using fuzzy neural network," Engineering, vol. 6, pp. 27-33, 2014.

[12] J. Y. Li, K. Wang, and Y. Li, "Automatic gauge control in rolling process based on multiple Smith predictor models," Abstract and Applied Analysis, vol. 2014, Article ID 872418, 10 pages, 2014.

[13] P. Kucsera and Z. Béres, "Hot rolling mill hydraulic gap control (HGC) thickness control improvement," Acta Polytechnica Hungarica, vol. 12, no. 6, pp. 93-106, 2015.

[14] AutoForm, "Robust springback compensation success at Shanghai Volkswagen," 2016, http://www.autoform.com/ blog/robust-springback-compensation-success-at-shanghaivolkswagen.

[15] R. Ankenas and R. Barauskas, "Finite element investigation on parameters influencing the springback during sheet metal forming," Mechanika, vol. 5, no. 61, pp. 57-61, 2006.

[16] R. H. Wagoner and M. Li, "Simulation of springback: through-thickness integration," International Journal of Plasticity, vol. 23, pp. 345-360, 2007.

[17] S. Sumikawa, A. Ishiwatari, J. Hiramoto, and T. Urabe, "Improvement of springback prediction accuracy using material model considering elastoplastic anisotropy and Bauschinger effect," Journal of Materials Processing Technology, vol. 230, pp. 1-7, 2016. 
[18] J. L. Wang, M. W. Fu, and J. Q. Ran, “Analysis of the size effect on springback behavior in micro-scaled U-bending process of sheet metals," Advanced Engineering Materials, vol. 16, no. 4, pp. 421-432, 2014.

[19] A. Diehl, U. Engel, and M. Geiger, "Spring-back behaviour of thin metal foils in free bending processes," in Proceedings of the 1st International Conference on Multi-Material Micro Manufacture, pp. 147-150, Germany, 2005.

[20] C. P. Jiang and C. C. Chen, "Grain size effect on the springback behavior of the microtube in the press bending process," Materials and Manufacturing Processes, vol. 27, pp. 512-518, 2012.

[21] P. A. Eggertsen and K. Mattiasson, "Material modelling for accurate springback prediction," International Journal of Material Forming, vol. 2, no. 1, pp. 793-796, 2009.

[22] N. Manopulo, P. Peters, and P. Hora, "Assessment of advanced constitutive modeling approaches for conventional deep drawing processes," in Proceedings of the 8th Forming Technology Forum, pp. 23-27, Zurich, Switzerland, June 2015.

[23] W. Prager, "A new method of analyzing stresses and strains in work hardening plastic solids," Journal of Applied Mechanics, vol. 23, pp. 493-496, 1956.

[24] H. Ziegler, "A modification of Prager's hardening rule," Quarterly of Applied Mathematics, vol. 17, no. 1, pp. 55-65, 1959.

[25] P. J. Amstrong and C. O. Frederick, "A mathematical representation of the multiaxial Bauschinger effect," G.E.G.B. Report RD/B/N 731, 1966.

[26] J. L. Chaboche, "Time-independent constitutive theories for cyclic plasticity," International Journal of Plasticity, vol. 2, no. 2, pp. 149-188, 1986.

[27] N. Ohno and J. D. Wang, "Kinematic hardening rules with critical state of dynamic recovery, Part I: formulation and basic features for ratchetting behavior," International Journal of Plasticity, vol. 9, pp. 375-390, 1993.

[28] N. Ohno and J. D. Wang, "Kinematic hardening rules with critical state of dynamic recovery, Part II: application to experiments of ratchetting behavior," International Journal of Plasticity, vol. 9, pp. 391-403, 1993.

[29] K. Chung and O. Richmond, "A deformation theory of plasticity based on minimum work paths," International Journal of Plasticity, vol. 9, pp. 907-920, 1993.

[30] B. K. Chun, J. T. Jinn, and J. K. Lee, "Modeling the Bauschinger effect for sheet metals, Part I: Theory," International Journal of Plasticity, vol. 18, pp. 571-595, 2002.

[31] B. K. Chun, H. Y. Kim, and J. K. Lee, "Modeling the Bauschinger effect for sheet metals, Part II: Applications," International Journal of Plasticity, vol. 18, pp. 597-616, 2002.

[32] R. D. Krieg, "A practical two surface plasticity theory," Journal of Applied Mechanics, vol. 42, no. 3, pp. 641-646, 1975.

[33] Y. F. Dafalias and E. P. Popov, "Plastic internal variables formalism of cyclic plasticity," Journal of Applied Mechanics, vol. 43, pp. 645-651, 1976.

[34] D. L. McDowell, "A two surface model for transient nonproportional cyclic plasticity: Part 1 development of appropriate equations," Journal of Applied Mechanics, vol. 52, pp. 298-302, 1985.

[35] D. K. Kim and J. Kim, "A two-surface viscoplastic model for the structural steel," Latin American Journal of Solids and Structures, vol. 14, no. 6, pp. 1000-1016, 2017.
[36] K. Hashiguchi, "A mathematical modification of two surface model formulation in plasticity," International Journal of Solids and Structures, vol. 24, no. 10, pp. 987-1001, 1988.

[37] Z. Mróz, "On the description of anisotropic workhardening," Journal of the Mechanics and Physics of Solids, vol. 15, pp. 163-175, 1967.

[38] H. N. Lu, D. B. Wei, Z. Y. Jiang, X. H. Liu, and K. I. Manabe, "Modelling of size effects in microforming processes with consideration of grained heterogeneity," Computational Materials Science, vol. 77, pp. 44-52, 2013.

[39] Z. Y. Jiang, J. W. Zhao, H. Lu et al., "Influences of temperature and grain size on the material deformability in microforming process," International Journal of Material Forming, vol. 10, pp. 753-764, 2017.

[40] J. G. Liu, M. W. Fu, and W. L. Chan, "A constitutive model for modelling of the deformation behavior in microforming with a consideration of grain boundary strengthening," Computational Materials Science, vol. 55, pp. 85-94, 2012.

[41] Q. Wang, X. H. Dong, H. M. Zhang, H. Z. Li, and Y. Shen, "Constitutive model for thin sheet metal with one or several grains across thickness in micro-forming," Transactions of Nonferrous Metals Society of China, vol. 23, pp. 1428-1434, 2013.

[42] L. Sun and R. H. Wagoner, "Complex unloading behavior: nature of the deformation and its consistent constitutive representation," International Journal of Plasticity, vol. 27, pp. 1126-1144, 2011.

[43] R. H. Wagoner, L. Sun, J. H. Sung et al., "Draw-bend and springback of advanced high strength steels and related constitutive model," in Proceedings of 2009 NSF Engineering Research and Innovation Conference, Honolulu, Hawaii, 2009.

[44] J. Hu, X. X. Li, K. Chung, and R. Yao, "Spring-back evaluation of stretch bending process based on Chaboche combined isotropic-kinematic hardening laws," Advanced Materials Research, vol. 204-210, pp. 1745-1750, 2011.

[45] L. Sun, J. H. Kim, and R. H. Wagoner, "Non-proportional hardening of dual phase steels and its constitutive representation," in Proceedings of IDDRG 2009 International Conference, pp. 119-130, Golden, USA, 2009.

[46] H. Badnava, S. M. Pezeshki, K. F. Nejad, and H. R. Farhoudi, "Determination of combined hardening material parameters under strain controlled cyclic loading by using the genetic algorithm method," Journal of Mechanical Science and Technology, vol. 26, no. 10, pp. 3067-3072, 2012.

[47] J. L. Chaboche, "Constitutive equations for cyclic plasticity and cyclic viscoplasticity," International Journal of Plasticity, vol. 5, pp. 247-302, 1989.

[48] A. Ghaei, Modeling springback in stamped automotive structures, PhD Thesis, University of Windsor, Canada, 2009.

[49] Abaqus 6.11 Tutorials, Dassault Systèmes, 2011.

[50] G. J. Hu, K. S. Zhang, and S. H. Huang, "Numerical integration algorithm for the rate-dependent Chaboche model," Journal of Guangxi University (Natural Science Edition), vol. 36, no. 1, pp. 166-171, 2011.

[51] M. G. Lee, D. Y. Kim, C. M. Kim, M. L. Wenner, R. H. Wagoner, and K. S. Chung, "A practical two-surface plasticity model and its application to spring-back prediction," International Journal of Plasticity, vol. 23, pp. 1189-1212, 2007.

[52] G. T. Yang, Introduction to Elasticity and Plasticity, Tsinghua University Press, Beijing, China, 2004.

[53] J. Xu, B. Guo, D. B. Shan, M. X. Li, and Z. L. Wang, "Specimen dimension and grain size effects on deformation behavior in 
micro tensile of SUS304 stainless steel foil," Materials Transactions, vol. 54, no. 6, pp. 984-989, 2013.

[54] F. J. Qu, Z. Y. Jiang, and W. Z. Xia, "Evaluation and optimisation of micro flexible rolling process parameters by orthogonal trial design," International Journal of Advanced Manufacturing Technology, vol. 95, no. 1-4, pp. 143-156, 2018.

[55] https://www.voronoi.com/wiki/index.php?title=Threedimensional_Voronoi_Diagram, 2018. 


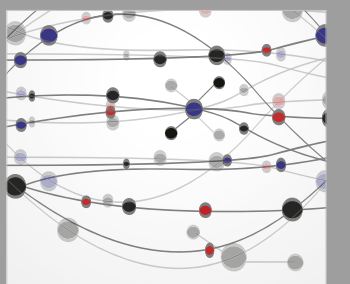

The Scientific World Journal
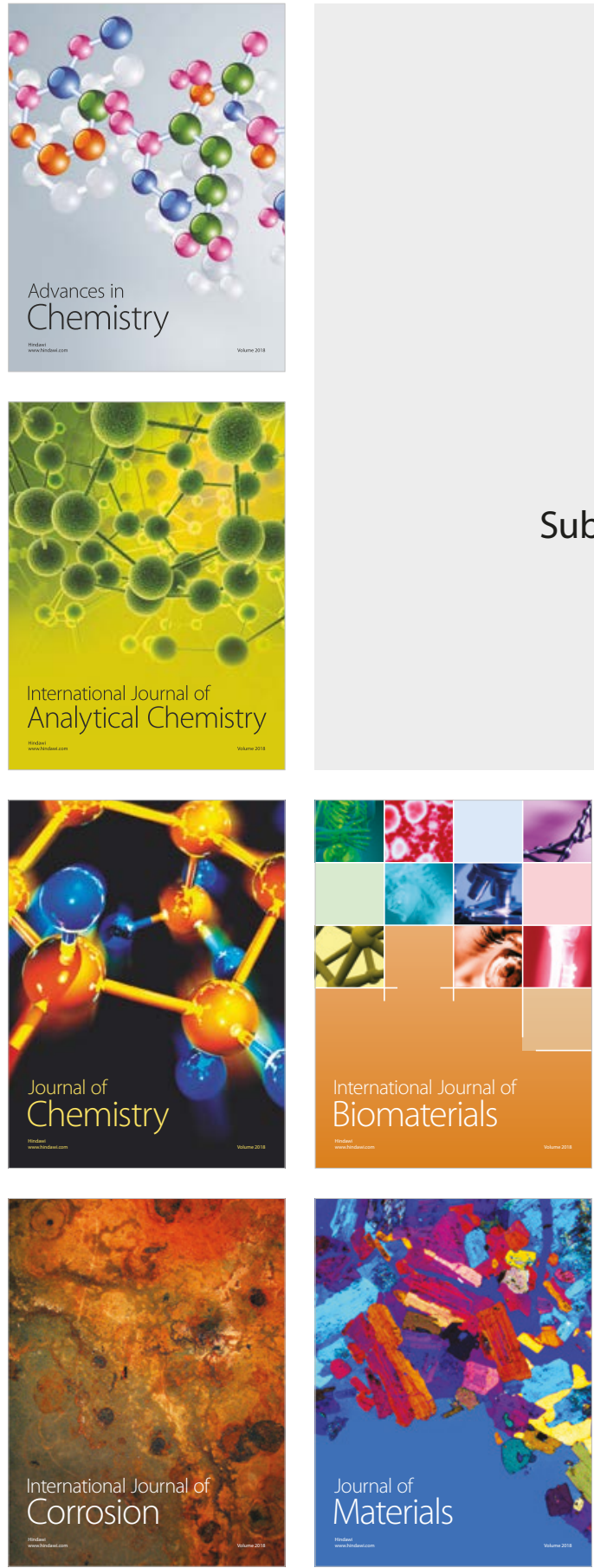

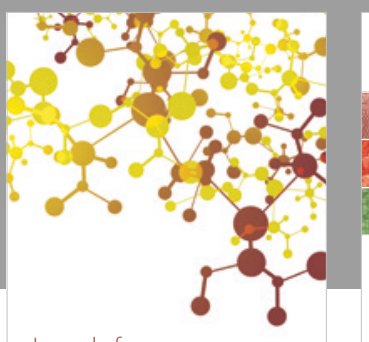

Journal of

Applied Chemistry
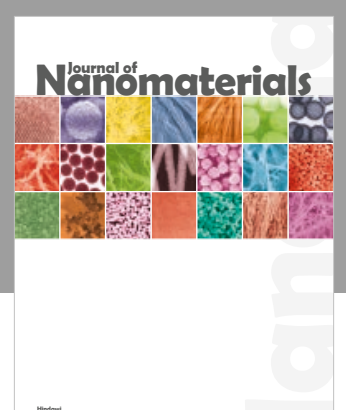

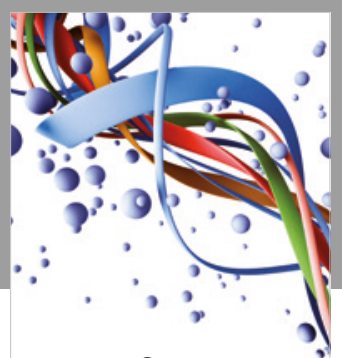

Scientifica

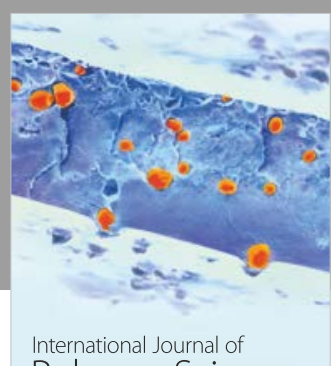

Polymer Science

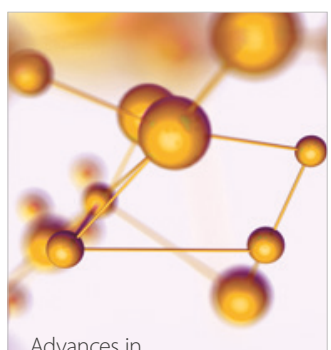

Physical Chemistry
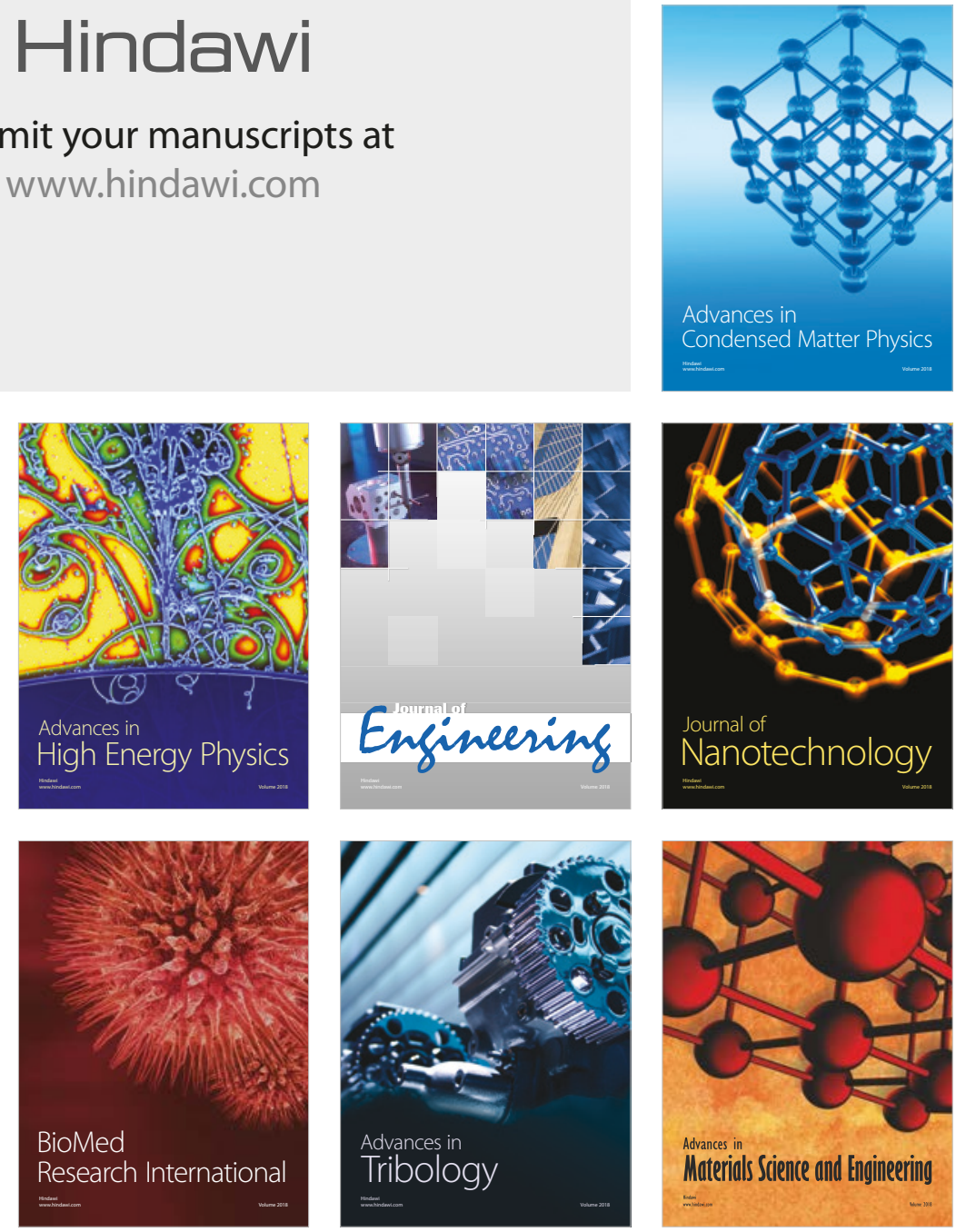